\title{
PREFACE
}

\section{Marine Biodiversity Records}

Marine Biodiversity Records www.journals.cambridge.org/ mbd is a complementary online-only sister journal to the Journal of the Marine Biological Association and was launched in April 2009. It is a response to the growing interest in research on the identification of marine organisms in locations where they have not formerly been found, as well as the effects of human activities on the ecology and distribution of marine and estuarine species.

The new online journal evolved from the JMBA2 Marine Biodiversity Records online resource which was published from 2005 on the MBA website (www.mba.ac.uk/jmba/jmba2biodiversityrecords.php) as a free peer-reviewed resource to collate these valuable records for the marine community. Lists of the papers published online were printed in the end of year issues of the Journal of the Marine Biological Association as a guide to readers.

The new formal journal includes original research articles and commissioned reviews of changes in geographical range of species, the effects of the introduction of novel species to ecosystems, the effects of pollution on established ecosystems, policy and implementation of conservation issues, effects of other human activities, including aquaculture, biodiversity management and tourism. It also documents range extensions of species, invasion by alien species and temperature-induced diseases, resulting from climate changes affecting the marine and brackish water environment and where appropriate taxonomic and faunistic studies.

For taxonomic descriptions to comply with the regulations of the International Code of Zoological Nomenclature: http://www.iczn.org/iczn/index.jsp and the International Code of Botanical Nomenclature http://ibot.sav.sk/icbn/ main.htm the following papers are included here in printed format.

Alexander Kieneke and Julia Zekely (2008). Desmodasys abyssalis sp. nov.-first record of a deep-sea gastrotrich from hydrothermal vents. Marine Biodiversity Records, $\mathbf{1}$, e88 doi:10.1017/S1755267207008950, Published Online by Cambridge University Press 25 Feb 2009.

R.M. Rocha and N.Y.K. Bonnet (2009) Eudistoma clavatum sp. nov. (Tunicata: Ascidiacea: Polycitoridae) from Brazil. Marine Biodiversity Records, 2, e3 doi:10.1017/ S1755267208000031, Published Online by Cambridge University Press 03 Mar 2009. 